regard to adherence and exacerbation measurements, designs and analysis precluded a formal meta-analysis. Although effect measures varied, good adherence was associated with fewer severe asthma exacerbations in high-quality studies.

Conclusion Good adherence is associated with a lower risk of severe asthma exacerbations. Future studies should use standardised methodology to assess adherence and inhaler technique.

\section{P153 DOES ASTHMA CONTROL, MOOD DISTURBANCE OR HEALTH STATUS INFLUENCE DAILY PHYSICAL ACTIVITY LEVELS IN PATIENTS WITH SEVERE ASTHMA?}

${ }^{1} \mathrm{~T}$ Pandya, ${ }^{2} \mathrm{~S}$ Majd, ${ }^{2} \mathrm{~S}$ Hewitt, ${ }^{2} \mathrm{~T}$ Harvey-Dunston, ${ }^{2} \mathrm{PH}$ Bradding, ${ }^{2} \mathrm{RH}$ Green, ${ }^{2} \mathrm{~S} J$ Singh, ${ }^{2}$ RA Evans. 'Manchester Medical School, Manchester, UK; ${ }^{2}$ Leicester NIHR Biomedical Research Unit, Glenfield Hospital, Leicester, UK

\subsection{6/thoraxjnl-2016-209333.296}

Introduction We aimed to assess the level of daily physical activity and investigate the relationship with asthma control, mood disturbance and health status in patients with severe asthma.

Methods Patients with severe asthma (step 4-5 of the British Thoracic Society guidelines), MRC dyspnoea grade $\geq 2$, were recruited from specialists in difficult-to-treat asthma. All patients were asked to wear SensewareTM activity monitor for seven days during waking hours with a minimum data requirement of eight hours per day for four days. ${ }^{1}$ Participants completed the Asthma Control Questionnaire (ACQ), Hospital Anxiety and Depression Scale (HADS), Chronic Respiratory Questionnaire (CRQ) and Asthma Quality of Life Questionnaire (AQLQ). Pearson's correlation coefficient was used to assess the relationship between physical activity, asthma control, mood disturbance and health status.

Results 45 participants (24 female, mean [SD] age 54 [13] yr, BMI 32 [7] kg/m ${ }^{2}$ ) provided written consent and physical activity data was available for 41 patients. The mean (SD) number of days of physical activity data available was 6.1 [1.9] days. The mean (SD) number of steps per day was 5258 [3030] with only 84 [82] active minutes. Only 16 patients achieved any moderate physical activity (3-4.5 metabolic equivalents [METS]) and for less than six minutes per day.

The mean [SD] ACQ was 13.6 [6.1], HADS anxiety and depression domains 6.5 [4.9] and 4.5 [2.8], respectively, CRQ Dyspnoea domain 3.4 [1.5], AQLQ environmental, symptoms, activity and emotional domains of 4.9 [1.4], 5.0 [1.4], 5.0 [1.2] and 4.9 [1.5], respectively. Table 1 shows the correlations between steps per day, and measures of asthma control, mood disturbance, and health status.

Abstract P153 Table 1 Relationship between steps per day and asthma control, mood disturbance and health status

\begin{tabular}{lll}
\hline Questionnaire & Correlation coefficient & $\boldsymbol{P}$ value \\
\hline ACQ & -0.16 & 0.28 \\
HADS - Anxiety & -0.17 & 0.28 \\
HADS - Depression & -0.13 & 0.41 \\
CRQ - Dyspnoea & 0.23 & 0.14 \\
AQLQ Activity & 0.34 & 0.02 \\
AQLQ Emotional & 0.17 & 0.26 \\
AQLQ Symptoms & 0.10 & 0.51 \\
AQLQ Environmental & 0.06 & 0.71 \\
AQLQ mean & 0.15 & 0.33 \\
\hline
\end{tabular}

Conclusions Patients with severe asthma demonstrated low levels of physical activity but there were no relationships with asthma control, mood disturbance or health status.

\section{REFERENCE}

1 Demeyers $\mathrm{H}$, et al. Chest 2014;146(2):318-27.

\section{P154 SAFETY OF TIOTROPIUM IN PRE-SCHOOL CHILDREN WITH SYMPTOMATIC PERSISTENT ASTHMA}

${ }^{1} \mathrm{H}$ Bisgaard, ${ }^{2} \mathrm{M}$ Vandewalker, ${ }^{3} \mathrm{~L}$ Graham, ${ }^{4} \mathrm{P}$ Moroni-Zentgraf, ${ }^{4} \mathrm{M}$ Engel, ${ }^{4} \mathrm{G}$ El Azzi, ${ }^{5} \mathrm{SD}$ Vulcu, ${ }^{6} \mathrm{H}$ Finnigan, ${ }^{7}$ EJLE Vrijlandt. ${ }^{1}$ University of Copenhagen, Department of Clinical Medicine, Gentofte Hospital, Copenhagen, Denmark; ${ }^{2}$ Clinical Research of the Ozarks, Inc., Columbia, MO, USA; ${ }^{3}$ Children's Healthcare of Atlanta, Atlanta, GA, USA; ${ }^{4}$ TA Respiratory Diseases, Boehringer Ingelheim Pharma GmbH and Co. KG, Ingelheim am Rhein, Germany; ${ }^{5}$ Translational Medicine and Clinical Pharmacology, Boehringer Ingelheim Pharma GmbH and Co. KG, Biberach an der Riss, Germany; ${ }^{6}$ Clinical Development and Medical Affairs/TA Respiratory Diseases, Boehringer Ingelheim Ltd, Bracknell, UK; ${ }^{7}$ Department of Paediatric Pulmonology and Paediatric Allergy, Beatrix Children's Hospital, University Medical Centre Groningen, University of Groningen, Groningen, The Netherlands

\subsection{6/thoraxjnl-2016-209333.297}

Introduction and objectives Asthma is the most common chronic disease of childhood (GINA 2015). For pre-school children whose asthma symptoms are not well controlled on inhaled corticosteroids, limited options are available for further treatment. Here, we evaluated the safety of once-daily (QD) tiotropium Respimat ${ }^{\circledR}$ (tioR) in patients aged 1-5 years with symptomatic persistent asthma.

Methods A Phase II/III, randomised, double-blind, placebo-controlled, parallel-group trial (NCT01634113) of tioR $5 \mu \mathrm{g}$, tioR $2.5 \mu \mathrm{g}$ or placebo Respimat ${ }^{\circledR}$ (pboR), administered QD in the afternoon for 12 weeks, each as add-on to usual maintenance therapy. Safety data, including post hoc analysis of a composite exacerbation end point derived from adverse events (AEs), are reported.

Results No AEs leading to treatment discontinuation or death were reported. The proportion of patients with any AEs was higher with pboR (73.5\%) than with tioR $5 \mu \mathrm{g}(58.1 \%)$ and 2.5

Abstract P154 Table 1 Composite asthma endpoint: Asthma exacerbation (broad) with pneumonia plus asthma worsening

\begin{tabular}{|c|c|c|c|}
\hline \multirow{5}{*}{$\begin{array}{l}\text { Composite end point } \\
\text { MedDRA preferred terms }\end{array}$} & \multicolumn{3}{|c|}{ Patients, n (\%) } \\
\hline & Tiotropium & Tiotropium & Placebo \\
\hline & Respimat $^{\oplus} 5 \mu \mathrm{g}$ & Respimat $^{\oplus} 2.5 \mu \mathrm{g}$ & Respimat \\
\hline & QD & QD & QD \\
\hline & $(n=31)$ & $(n=36)$ & $(n=34)$ \\
\hline Asthma exacerbation (broad)/ & $9(29.0)$ & $12(33.3)$ & $19(55.9)$ \\
\hline \multicolumn{4}{|l|}{ worsening + pneumonia } \\
\hline Asthma & $2(6.5)$ & $5(13.9)$ & $10(29.4)$ \\
\hline Bronchitis & $2(6.5)$ & $1(2.8)$ & $4(11.8)$ \\
\hline Bronchopneumonia & 0 & 0 & $1(2.9)$ \\
\hline Cough & $2(6.5)$ & $4(11.1)$ & $3(8.8)$ \\
\hline Dyspnoea & $1(3.2)$ & 0 & 0 \\
\hline Pneumonia & 0 & $1(2.8)$ & $2(5.9)$ \\
\hline Viral respiratory tract infection & $3(9.7)$ & $3(8.3)$ & $4(11.8)$ \\
\hline Wheezing & 0 & $2(5.6)$ & 0 \\
\hline
\end{tabular}

Treated set. Percentages calculated using total number of patients per treatment as denom inator. AE preferred terms defined by Medical Dictionary for Regulatory Activities version 17.1. 